\title{
Family Relationships and the Development of a Predisposition to Violence*
}

\section{Introduction}

In family, people grow and develop physically, psychologically, and spiritually. For the optimal holistic growth of an individual who will build a healthy society, family life should be as close to the ideal as possible: however, contemporary families often find themselves in a vicious cycle of different kinds of distress, marked with broken relationships and interpersonal wounds. If this dimension is seriously affected, children's development is endangered in its very core, since the relations with parents from the first days of their lives are crucial for their development. In such an environment we can find early etiology for different kinds of psychopathology and possibilities for dysfunctional behavior in relationships, such as violence.

* The author acknowledges partial financial support from the Slovenian Research Agency (project No. J5-9349). 


\section{The significance of connection with parents and attach- ment in early childhood}

Family is the first social environment that most deeply influences and directs the growth of a young person. Family can be defined as an emotional-social system which is, in addition to blood ties, connected with interpersonal affective bonds, and its fundamental task is to create a warm and secure environment where each member is able to feel that s/he belongs, to fulfill her/ his basic needs, and to become an independent, healthy, and self-confident person. ${ }^{1}$ In the family, a child gathers new life experiences, is educated and socialized. Family, parenting and relationships from one's earliest life period are irreplaceable, and for healthy development, a child needs her/his parents who are her/his first and most important educators. ${ }^{2}$ The dynamics of these primary relationships will dictate every new relationship, because they are engraved in the child's intrapsychic world. ${ }^{3}$

The development of an individual's intrapsychic structure is based upon an individual's experience of relationships with significant others in their family of origin during their childhood. The mother-child relationship is paramount here. ${ }^{4}$ Winnicott ${ }^{5}$, for instance, refers to the mother-child relationship as an empathic unit, which is dynamic, alive, interactive and oriented towards more than just the satisfaction of biological needs. This unit proves essential to the child as it enables the development of a healthy and vibrant personality, capable of experiencing satisfaction, freshness,

\footnotetext{
C. Gostečnik, Srečal sem svojo družino, Ljubljana 1999, Brat Frančišek in Frančiškanski družinski inštitut, pp. 185-186.

2 N. Rijavec Klobučar, The role of spirituality in transition to parenthood: qualitative research using transformative learning theory, "Journal of Religion and Health" 55 (2016) 4, pp. 1345-1358.

3 C. Gostečnik, Psihoanaliza in religiozno izkustvo, Ljubljana 2005, Brat Frančišek in Frančiškanski družinski inštitut, pp. 153-154.

4 While this contribution will focus on the mother-child relationship, the capacity to emotionally attune to an infant is not gender specific. The care and regulation of infants also can be done by any adult who is attuned, available, and committed to providing continuity of care. Increasing numbers of fathers are participating in this care and in some cases even becoming the primary caregiver (S. Gerhard, Why love matters, London 2004, Routledge, p. 207).

5 Cf. D. W. Winnicott, Playing and reality, London 1971, Routledge; D. W. Winnicott, On the child, Cambridge 2002, Perseus Books Group.
} 
playfulness and creativeness. Bowlby ${ }^{6}$ also emphasizes that an individual is organically determined by the attachment mechanism, and that the largest source of stress and developmental pathologies is indeed the absence of mother or some other attachment figure. Bowlby's attachment theory and other similar research, especially research concerning the neurobiological basis of attachment ${ }^{7}$, formed the basis for broader importance of attachment and appropriate contact with the primary caregiver: it creates an innate system in the brain which develops by influencing and organizing the system for motivation, emotions and memory on the basis of parents or caregivers.

When emphasizing the importance of quality relationship, we primarily think of sensitive and empathetic parenting where parents are in-tune, responsive, and attentive, where the child feels safe, being able to develop compassion and maintain the vividness of spirit. ${ }^{8}$ Many research on mothers (parents) and infants confirm that the mother (parents) is the individual who directly influences the development of the child's brain, and that this influence is positive when the mother affectively attunes to her child. ${ }^{9}$ Parents have innate responsiveness to the child, so that they can provide her/him with whatever the child absolutely needs in a given moment. ${ }^{10}$ A child whose basic physical and emotional needs are adequately met will feel that s/he can rely on her/his parents. With parents who are well-tuned, responsive, loving, attentive, sensitive, and at the same time standing up for what they believe in, children feel accepted; and they develop selfawareness and self-image based on these messages. Parents who seriously and respectfully embrace their child as s/he is and as s/he feels, who sense the child's distress although they may not see a sound reason behind it, and who, at the same time, maintain adequate boundaries give the child the sense of security in the outer world, as well as the feeling that $s /$ he is seen

6 Cf. J. Bowlby, Attachment and loss: Vol. 3. Loss, sadness and depression, New York 1973, Basic Books; J. Bowlby, Attachment and loss: Vol. 2. Separation, anxiety and anger, New York 1980, Basic Books; J. Bowlby, Attachment and loss: Vol. 1. Attachment, New York 1982, Basic Books.

7 Cf. A. N. Schore, Affect regulation and the repair of the self, New York 2003, W. W. Norton.

8 B. Simonič, A. Poljanec, Building motherhood in the young mothers' group, "Child care in practice" 20 (2014) 3, p. 272.

9 Cf. D. N. Stern, The interpersonal world of the infant, New York 1985, Basic Books.

10 B. Simonič, Tenderness and its meaning in interpersonal relationships and pastoral care, »Bogoslovni vestnik« 78 (2018) 1, pp. 211-213. 
and heard, 'made known', which is crucial for her/his self-esteem due to the feeling that her/his 'self' is authentic and real. ${ }^{11}$

\section{A psychoneurobiological model of development}

As already stated, not only are all these early experiences of important attachment relationships recorded deeply in our unconsciousness: they also influence the development of the individuals' organic system in the brain, which is responsible for processing unconscious information throughout life. The foundations for an adult individual's emotional style and emotional resources are established during pregnancy and in the first two years of life. This is when the 'social brain' is shaped, the part of the brain which learns how to manage feelings in line with other people, as well as the development of stress response, immune response and neurotransmitter systems which all affect future emotional life. ${ }^{12}$ The child's primary relationship, especially with the mother (or other primary caregiver), thus provides the basis for how the circuits of emotional processing will form in the child's brain. This will also determine the individual's greater or lesser capacity to enter into emotional relationships later in life. ${ }^{13}$ The connection between the child and the adult is a crucial necessity, while at the same time it provides the space for the child's development. The depth and quality of this connection comprises the entire sphere of the capacity to establish and maintain relationships, with regard to the capacity to observe, to be empathic as well as to regulate emotional and bodily stances. ${ }^{14}$

At birth, the baby is unfinished, although he has all the anatomical parts, he is like raw material with a genetic blueprint and a unique range of possibilities, which have to develop in certain ways through experiences, especially social ones. ${ }^{15}$ Experiences will activate the neural pathways, and

11 Cf. B. Beebe, F. Lachmann, S. Markese, L. Bahrick, On the origins of disorganized attachment and internal working models: Paper I. A dyadic systems approach, "Psychoanalytic Dialogues" 22 (2012) 2, 253-272.

12 S. Gerhard, Why love matters, London 2004, Routledge, p. 3.

13 Cf. A. N. Schore, Affect regulation and the repair of the self, New York 2003, W. W. Norton.

14 B. Simonič, A. Poljanec, Building motherhood in the young mothers' group, "Child Care in Practice" 20 (2014) 3, pp. 270-285.

15 S. Gerhard, Why love matters, London 2004, Routledge, p. 18. 
this activation directly influences how connections are formed within the brain. Experiences early in life may be especially crucial in organizing the way the basic regulatory structures in brain develop. Everyday experiences thus shape brain structure, because they activate certain pathways in the brain, strengthening existing connections and creating new ones. Early years are the period when the basic 'architecture' in the brain is laid down. ${ }^{16}$ "Relationship experiences have a dominant influence on the brain because the circuits responsible for social perception are the same as or tightly linked to those that integrate the important functions controlling the creation of meaning, the regulation of bodily states, the modulation of emotion, the organization of memory, and the capacity for interpersonal communication."17

The psychoneurobiological perspective on development focuses on the first two years of life, when the human brain grows faster than in any other stage of life. This is also a period when attachment bonds are formed most intensively. The early social environment (relationships with primary caregivers) thus directly influences the final wiring of the circuits in the infant's brain that are responsible for the future social and emotional life. The attachment relationships directly shape the maturation of the child's right brain, a particular system in the prefrontal areas of the right brain which is responsible for the regulation of emotions, including positive emotions (e.g. joy and interest) as well as negative emotions such as fear and aggression. ${ }^{18}$

Patterns of secure attachment relationships experiences will result in organization of an adaptive regulatory system in the prefrontal areas of the right hemisphere. The efficient functioning in this part of the brain is central to the baby's growing capacity for self-regulation, the ability to flexibly regulate stressful emotional states through interactions with other humans and autoregulation in autonomous contexts. This is how a secure attachment relationship (episodes of tenderness, attunement and synchrony where parents engagement in intuitive, nonconscious, facial, vocal, and gestural preverbal communications with baby) facilitates right brain development, promotes efficient affect regulation, and fosters adaptive

\footnotetext{
16 D. J. Siegel, The developing mind, New York 2012, Norton, pp. 22-23.

D. J. Siegel, The developing mind, New York 2012, Norton, p. 33.

18 A. N. Schore, Early relational trauma, disorganized attachment, and the development of a predisposition to violence, in: M. F. Solomon, D. J. Siegel (eds.), Healing trauma, New York 2003, W. W. Norton \& Company, pp. 112-113.
} 
infant mental health. ${ }^{19}$ To do this, the mother or primary caregiver has to be psychobiologically attuned to the dynamic 'crescendos' and 'decrescendos' of the infant's bodily-based internal states and arousal, and to respond to them (e.g. to calm the baby, to feed him, to put him to sleep, etc.), because in an infant's body there is nothing mature enough that can appropriately regulate his stress (negative affective bodily states of hyperaroused protest or hypoaroused despair towards a reestablished state of positive affect). A maternal or caregiver's sensitivity thus acts as an external organizer of the infant's biobehavioral regulation. ${ }^{20}$ On the basis of this, at some point in development, the infant becomes self-regulating through the development of internal regulatory mechanisms. ${ }^{21}$

These affective communications impact the developing brain, especially the rapidly developing limbic areas and cortical related areas of the right brain that myelinate in the first two years. During relationship experiences between the baby and mother, the mother coregulates the infant's postnatally developing autonomic nervous system, when it is aroused. In this manner, the optimally regulated communications in secure attachment experiences directly imprint the postnatally maturing limbic system (in the central nervous system) that processes and regulates social-emotional stimuli, and the autonomic nervous system that generates the somatic aspects of emotion. The higher regulatory system of the right hemisphere forms extensive reciprocal connections with the limbic and autonomic nervous systems. These limbic-autonomic circuits in the right hemisphere, which is dominant for the human stress response, is directly influenced by the attachment relationship, so maternal care regulates the development of the child's response to stress. ${ }^{22}$

19 A. N. Schore, Early relational trauma, disorganized attachment, and the development of a predisposition to violence, in: M. F. Solomon, D. J. Siegel (eds.), Healing trauma, New York 2003, W. W. Norton \& Company, p. 204.

20 A. N. Schore, Early relational trauma, disorganized attachment, and the development of a predisposition to violence, in: M. F. Solomon, D. J. Siegel (eds.), Healing trauma, New York 2003, W. W. Norton \& Company, pp. 116-117.

21 G. W. Kraemer, M. H. Ebert, D. E. Schmidt, W. T. McKinney, Strangers in a strange land: A psychobiological study of infant monkey before and after separation from real or inanimate mothers, "Child Development" 62 (1991) 3, p. 561.

22 A. N. Schore, Early relational trauma, disorganized attachment, and the development of a predisposition to violence, in: M. F. Solomon, D. J. Siegel (eds.), Healing trauma, New York 2003, W. W. Norton \& Company, pp. 118-119. 
The prefrontal cortex has a unique role, because it links the sensory areas of the cortex with the emotional and survival-oriented subcortex. One part of prefrontal cortex is the orbitofrontal cortex, which has a key role in emotional life. If this part is impaired, social life is undermined (people cannot relate to others sensitively, become oblivious to social and emotional cues, they can be sociopathic, dissociative, etc.). The orbitofrontal cortex, together with other parts of prefrontal cortex and limbic system, is responsible for 'emotional intelligence.' It is also very involved with managing emotional behaviors and responding to other people and their emotional signals. This role is achieved through its strong neural connections with the subcortical basic emotional systems and has an important role in the control of emotional responses. The ability to hold back and defer immediate impulses and desires is the basis for our self-control and mature reactions, as well as our capacity for empathy. ${ }^{23}$ And it is very important to emphasize that the maturation of the orbitofrontal areas, the brain's central emotion regulating system, occurs completely postnatally. Their development is positively or negatively shaped by attachment experiences. ${ }^{24}$

\section{Long-term effects of early relational trauma}

Early trauma has a profound negative impact upon the developing personality. Trauma in infancy can be found in abuse and neglect, and there is evidence that neglect may be even more damaging than abuse. ${ }^{25}$ The experience of trauma in the first two years can be inflicted through the physical or interpersonal environment. However, it is established that social stressors are far more devastating than nonsocial stressors. Such traumatic experiences could be labelled as "relational trauma," which is usually not a single event; rather, it is cumulative and chronic, and most often comes from the primary caregivers. ${ }^{26}$

23 S. Gerhard, Why love matters, London 2004, Routledge, pp. 36-37.

24 A. N. Schore, Early relational trauma, disorganized attachment, and the development of a predisposition to violence, in: M. F. Solomon, D. J. Siegel (eds.), Healing trauma, New York 2003, W. W. Norton \& Company, p. 114.

25 T. Repič Slavič, C. Gostečnik, Relational family therapy as an aid toward resolving the trauma of sexual abuse in childhood in the process of separation in the couple relationship, "Journal of Marital and Family Therapy" 43 (2017) 3, p. 422.

26 A. N. Schore, The effects of early relational trauma on right brain development, affect regulation, and infant mental health, "Infant Mental Health Journal" 22 (2001) 1-2, p. 206. 
Its representation is in ongoing repetitive relational stressors present in a severely mis-attuned attachment relationship in the first two years of life. ${ }^{27}$ In human infancy, relational trauma interferes with the experience-dependent maturation of the brain's coping systems, and therefore, have a long-enduring negative impact on the developmental processes. ${ }^{28}$

Early traumatic dysregulating transactions with the social environment can be thus understood as relational trauma, and negatively impact the maturation of the brain. Traumatic attachment acts as a growth inhibiting environment for the experience-dependent maturation of the right hemisphere, which is in a critical period of growth in the first year of life, and is dominant in the unconscious processing of socioemotional information, the regulation of bodily states, the capacity to cope with emotional stress, the corporeal and emotional self and fast-acting regulatory operations. ${ }^{29}$ The processing and regulation of experiencing challenging and stressful situations are thus impaired. The brain, particularly its prefrontal cortex and the systems of the subcortex involved in emotion, plays a major role in monitoring experiences and adapting responses to it. In the case of stress, the body releases cortisol, a stress hormone, which proves to be a key player in our emotional lives. A baby in continuous and inappropriately regulated stress can be saturated with cortisol. There is some evidence that high levels of cortisol might be toxic to the developing brain over time. ${ }^{30}$ Too much cortisol can affect the development of the orbitofrontal part of the prefrontal cortex and subcortical structures (hippocampus, amygdala), which are responsible for reading social cues, emotional regulation and adapting behavior to social norms. ${ }^{31}$

27 A. N. Schore, Early relational trauma, disorganized attachment, and the development of a predisposition to violence, in: M. F. Solomon, D. J. Siegel (eds.), Healing trauma, New York 2003, W. W. Norton \& Company, p. 110.

28 Cf. A. N. Schore, The effects of early relational trauma on right brain development, affect regulation, and infant mental health, "Infant Mental Health Journal" 22 (2001) 1-2, pp. 201-269.

29 A. N. Schore, Early relational trauma, disorganized attachment, and the development of a predisposition to violence, in: M. F. Solomon, D. J. Siegel (eds.), Healing trauma, New York 2003, W. W. Norton \& Company, p. 113.

30 S. Gerhard, Why love matters, London 2004, Routledge, p. 66.

31 M. Dozier, M. Rutter, challenges to the development of attachment relationships faced by young children in foster and adoptive care, in: J. Cassidy, P. R. Shaver (eds.), Handbook of attachment, New York 2008, Guilford, p. 708; D. J. Siegel, The developing mind, New York 2012, Norton, p. 113. 
In sum: trauma and emotional neglect negatively affect the structure and function of the right hemisphere, subcortical structures and the prefrontal cortex. The right brain and subcortical structures are centrally involved in emotional processing, the prefrontal cortex plays a major role in affect regulation. ${ }^{32}$ It is no wonder that these people, as adults, suffer the consequences, which also destructively impact their lives and the lives of their loved ones. Later in life, children with a secure attachment history are capable of developing and maintaining more successful close relationships, especially with their parents, peers, and partners, than are insecure children; they develop a variety of desirable personality qualities in childhood, adolescence and adulthood; they are more likely to exhibit constructive forms of emotionality and emotion self-regulation; and they exhibit more positive self-regard in both explicit and implicit assessments of self-concept. ${ }^{33}$ Various adult disorders have their roots in babyhood; for instance, an individual can choose to eat too much or too little, consume too much alcohol, react to other people without thinking, fail to be empathic to others, make unreasonable emotional demands, become depressed, anxious, being ill, attack other physically etc., mainly because their capacity to manage their own feelings has been impaired by poorly developed emotion systems. ${ }^{34}$

\section{A psychoneurobiological view on the etiology of a pre- disposition to violence}

According to General Aggression Mode (GAM) ${ }^{35}$, the person and situation factors have impact on cognitions, feelings, and arousal, which in turn affect appraisal and decision processes, and that in turn influences aggressive or

32 D. Fosha, Dyadic regulation and experiential work with emotion and relatedness in trauma and disorganized attachment, in: M. F. Solomon, D. J. Siegel (eds.), Healing trauma, New York 2003, W. W. Norton \& Company, p. 222.

33 R. A. Thompson, Early attachment and later development familiar questions, new answers, in: J. Cassidy, P. R. Shaver (eds.), Handbook of attachment, New York 2008, Guilford, p. 361 .

34 S. Gerhard, Why love matters, London 2004, Routledge, p. 87.

35 J. J. Allen, C. A. Anderson, B. J. Bushman, The general aggression model, "Current Opinion in Psychology" 19 (2018) 1, p. 72. 
nonaggressive behavior. Person and situation factors can change a person's affect, cognition, and arousal, and this is the route how these three variables can lead to aggressive behavior, if they are inappropriately regulated. Any of the three variables can occur first and then influence the other two. Affect can influence cognition and arousal (feeling angry can lead to hostile thoughts and increase arousal), cognition and arousal can influence affect (interpreting a situation in a hostile manner can increase anger, which can increase arousal). ${ }^{36}$ It is interesting to consider that individuals who inappropriately regulate affects such as anger etc., may be more likely to behave aggressively in an attempt to repair, terminate, or avoid uncomfortable emotional states. ${ }^{37}$ It is essential to our wellbeing to be able to regulate (i.e. manage) the intensity of emotions, both positive and negative: otherwise we are in the state of dysregulation. Affect regulation is the way of managing emotions: how we handle sadness, joy, anger, excitement, challenge, or fear. Affect dysregulation develops when one is not able to feel one's emotions, when one is overwhelmed by emotions, or they remain unresolved. ${ }^{38}$

As we described earlier, the individual's capacity to process and regulate emotion/affect, fundamental to human relatedness, can be substantively affected in the case of early relational trauma. The heritage of traumatic relationships and neglect not only becomes evident in the dramatic disturbances of posttraumatic stress disorder, but is also known and felt in the devastating impairment of a baseline of well-being and in disturbances in social relationships, ${ }^{39}$ including violence. A growing body of studies indicates that traumatic childhood experiences provide the context for the roots of adult violence. ${ }^{40}$ The violent persons of the future are now babies ${ }^{41}$ who will have problems in appropriate affect regulation.

36 J. J. Allen, C. A. Anderson, B. J. Bushman, The general aggression model, "Current Opinion in Psychology" 19 (2018) 1, p. 77.

37 T. Roberton, M. Daffern, R. S. Bucks, Emotion regulation and aggression, "Aggression and Violent Behavior” 17 (2012) 1, p. 72.

38 L. Heller, A. LaPierre, Healing developmental trauma, Berkley 2012, North Atlantic Books, p. 14.

39 D. Fosha, Dyadic regulation and experiential work with emotion and relatedness in trauma and disorganized attachment, in: M. F. Solomon, D. J. Siegel (eds.), Healing trauma, New York 2003, W. W. Norton \& Company, p. 226.

40 A. N. Schore, Early relational trauma, disorganized attachment, and the development of a predisposition to violence, in: M. F. Solomon, D. J. Siegel (eds.), Healing trauma, New York 2003, W. W. Norton \& Company, p. 108.

41 S. Gerhard, Why love matters, London 2004, Routledge, p. 167. 
The quality of relationship with parents in early childhood influences brain development and also facilitates the learning of different types of regulatory strategies. A weakly developed prefrontal cortex has been found in a number of psychopathologies and negative behavioral strategies. Without a strong prefrontal cortex, the mechanisms of self-control, for soothing the self and to feel connected to others remain immature. ${ }^{42}$ Early developmental experiences that build cortical functions are investments that protect against the expression of violent or impulsive behavior. On the other hand, experiences that increase reactivity of the lower areas of the brain, such as relational trauma, will increase the capacity for impulsive emotional responses and the greater possibility of later violence..$^{43}$ Of course, all children who suffer from relational trauma in infancy will not become victimizers. However, in the background of most adult and adolescent violence we can find relational trauma inflicted on the babies these individuals once were. ${ }^{44}$

Inability to regulate strong emotions because of underdeveloped brain regulatory functions and coping capacities leads to violence. ${ }^{45}$ Aggression disorders represent a dysregulation of the brain's flight centers (subcortic limbic system). A developmentally immature hierarchical orbitofrontal system cannot regulate lower areas in the right brain, which generate positive and negative affective states, including aggressive states. ${ }^{46}$ Since right hemisphere subcortical activity is increased and unregulated due to impaired prefrontal cortex, this could predispose the individual to experience negative affect which fosters aggressive feelings, which in turn act as a general predisposition to violent behavior. ${ }^{47}$

It is important to mention that research on the neurobiology of affect regulation focuses not only on the orbitofrontal system in the brain, which

42 S. Gerhard, Why love matters, London 2004, Routledge, p. 108.

43 R. Karr-Morse, M. S. Wiley, Ghosts from the nursery, New York 2013, Atlantic Monthly Press, p. 168.

44 T. R. Verny, Tomorrow's baby, New York 2002, Simon \& Schuster, p. 201.

45 T. Brazelton, Preface, in: R. Karr-Morse, M. S. Wiley, Ghosts from the nursery, New York 2013, Atlantic Monthly Press, p. xiii.

46 A. N. Schore, Early relational trauma, disorganized attachment, and the development of a predisposition to violence, in: M. F. Solomon, D. J. Siegel (eds.), Healing trauma, New York 2003, W. W. Norton \& Company, p. 114.

47 A. Raine, J. R. Meloy, S. Bihrle, J. Stoddartd, L. Lacasse, M. S. Buchsbaum, Reduced prefrontal and increased subcortical brain functioning assessed using positron emission tomography in predatory and affective murderers, "Behavioral Sciences and the Law" 16 (1998) 3, p. 329. 
links the prefrontal cortex to the limbic system and modulates emotions, but also on the right hemisphere, where emotions of distress, sadness, and disgust originate. Dependent on the caregiver's ability to respond accurately and sensitively, the baby communicates her internal state through a repertoire of emotional signals. The caregiver's responsiveness literally shapes the patterns or circuits in the child's limbic system, which will ultimately be responsible for affect regulation. ${ }^{48}$ "This is our first model for a constructive, self-consoling pattern when faced with strong negative emotions. Fear or rage may frequently overwhelm a child who has not learned emotional regulation skills. Explosive aggression, freezing, or selfdestructive behavior may result from a child's disorganized efforts to handle strong feelings without a constructive experiential 'map'. As they mature, all children-like all adults-will be exposed to situations that will generate strong negative emotions of fear, anger, jealousy, or frustration. But here, in our first relationship, is the seat of our physiological and emotional patterning in regulating those emotions." 49 The capability to regulate emotion from childhood on serves as a protective factor against aggressive behavior. While this ability can be taught and built up later in life, basic patterns for handling negative and distressful emotional states are formed in the first two years of life.

\section{Conclusion}

"Nature needs nurture." ${ }^{50}$ Human beings are open systems, shaped by other people. Human psychological and mental systems are developed in relationship with other people - and this happens most intensively in infancy. It can be said that a human baby is the most socially influenced creature (or biological system) on earth. ${ }^{51}$ Biological and social factors are highly interactive in human development, particularly in its earliest stage.

48 Cf. A. N. Schore, The effects of early relational trauma on right brain development, affect regulation, and infant mental health, "Infant Mental Health Journal" 22 (2001) 1-2, pp. 201-269.

49 R. Karr-Morse, M. S. Wiley, Ghosts from the nursery, New York 2013, Atlantic Monthly Press, p. 208.

50 D. J. Siegel, The mindful brain, New York 2007, W. W. Norton \& Company, p. 30.

51 S. Gerhard, Why love matters, London 2004, Routledge, p. 10. 
Of course, an infant is influenced by genetics and environmental factors: but social factors, particularly the sensitive nurturing of a committed caregiver, interact with and actually alter biological elements (such as brain chemistry and brain tissue). It is of great importance not to reduce the relationship between biology, experience, and behavior. It could be very damaging to our communities and to our nation to be unaware of this reality. ${ }^{52}$ That's why it is crucial to consider and develop appropriate programs for early intervention and prevention, which could act also as a protective factor against a risk for aggressive behavior and violence. Prevention and intervention should begin even before birth, before the nursery, during pregnancy, and it should be extended through the perinatal and postnatal period. Such interventions should focus on preventing early relational trauma by improving the efficiency of psychobiological communication between the primary caregiver and the baby. Programs for effective parenting (in any field - pediatrics, psychiatry, psychology, social work, education, pastoral care, etc.) can create a developmental context for the transformation of attachment from insecure to secure, and in this way facilitate experience-dependent neurobiological maturation of the right brain, which is centrally included in the adaptive regulation of motivational states, including aggressive ones..$^{53}$ The information that (neuro)science has offered in recent decades is clear and cannot be denied - there is enormous opportunity to do something to provide more children with the optimal start so that they are optimally emotionally equipped to deal with life. This will also impact societal life and costs (e.g. managing the consequences of poor emotional regulation, the costs of crime, putting children in care, taking care of drug and substance abusers, etc.). ${ }^{54}$ Well-intentioned governments and policies have already recognized the need to support family life. These are indeed foundations for a healthy society.

52 R. Karr-Morse, M. S. Wiley, Ghosts from the nursery, New York 2013, Atlantic Monthly Press, p. 191.

53 A. N. Schore, Early relational trauma, disorganized attachment, and the development of a predisposition to violence, in: M. F. Solomon, D. J. Siegel (eds.), Healing trauma, New York 2003, W. W. Norton \& Company, pp. 146-148.

54 S. Gerhard, Why love matters, London 2004, Routledge, pp. 216-217. 


\section{Bibliography}

Allen J. J., Anderson C. A., Bushman B. J., The general aggression model, "Current Opinion in Psychology" 19 (2018) 1, pp. 75-80.

Beebe B., Lachmann F., Markese S., Bahrick L., On the origins of disorganized attachment and internal working models: Paper I. A dyadic systems approach "Psychoanalytic dialogues" 22 (2012), 2, pp. 253-272.

Bowlby J., Attachment and loss: Vol. 3. Loss, sadness and depression, New York 1973, Basic Books.

Bowlby J., Attachment and loss: Vol. 2. Separation, anxiety and anger, New York 1980, Basic Books.

Bowlby J., Attachment and loss: Vol. 1. Attachment, New York 1982, Basic Books.

Brazelton T., Preface, in: R. Karr-Morse, M. S. Wiley, Ghosts from the nursery, New York 2013, Atlantic Monthly Press, pp. ix-xvi.

Dozier M., Rutter M., Challenges to the development of attachment relationships faced by young children in foster and adoptive care, in: J. Cassidy, P. R. Shaver (eds.), Handbook of attachment, New York 2008, Guilford, pp. 698-717.

Fosha D., Dyadic regulation and experiential work with emotion and relatedness in trauma and disorganized attachment, in: M. F. Solomon, D. J. Siegel (eds.), Healing trauma, New York 2003, W. W. Norton \& Company, pp. 221-281.

Gerhard S., Why love matters, London 2004, Routledge.

Heller L., LaPierre A., Healing developmental trauma, Berkley 2012, North Atlantic Books.

Karr-Morse R., Wiley M. S., Ghosts from the nursery, New York 2013, Atlantic Monthly Press.

Kraemer G. W., Ebert M. H., Schmidt D. E., McKinney W. T., Strangers in a strange land: A psychobiological study of infant monkey before and after separation from real or inanimate mothers, "Child Development" 62 (1991) 3, pp. 548-566.

Raine A., Meloy J. R., Bihrle S., Stoddartd J., Lacasse L., Buchsbaum M. S., Reduced prefrontal and increased subcortical brain functioning assessed using positron emission tomography in predatory and affective murderers, "Behavioral Sciences and the Law" 16 (1998) 3, pp. 319-332. 
Repič Slavič T., Gostečnik C., Relational family therapy as an aid toward resolving the trauma of sexual abuse in childhood in the process of separation in the couple relationship, "Journal of Marital and Family Therapy" 43 (2017) 3, pp. 422-434.

Rijavec Klobučar N., The role of spirituality in transition to parenthood: qualitative research using transformative learning theory, "Journal of Religion and Health" 55 (2016) 4, pp. 1345-1358.

Roberton T., Daffern M., Bucks R. S., Emotion regulation and aggression, "Aggression and Violent Behavior" 17 (2012) 1, pp. 72-82.

Schore A. N., The effects of early relational trauma on right brain development, affect regulation, and infant mental health, "Infant Mental Health Journal" 22 (2001) 1-2, pp. 201-269.

Schore A. N., Affect regulation and the repair of the self, New York 2003, W. W. Norton.

Schore A. N., Early relational trauma, disorganized attachment, and the development of a predisposition to violence, in: M. F. Solomon, D. J. Siegel (eds.), Healing trauma, New York 2003, W. W. Norton \& Company, pp. 107-167.

Siegel D. J., The mindful brain, New York 2007, W. W. Norton \& Company.

Siegel D. J., The developing mind, New York 2012, Norton.

Simonič B., Poljanec A., Building motherhood in the young mothers' group, "Child Care in Practice" 20 (2014) 3, pp. 270-285.

Simonič B., Tenderness and its meaning in interpersonal relationships and pastoral care, "Bogoslovni vestnik" 78 (2018) 1, pp. 209-218.

Stern D. N., The interpersonal world of the infant, New York 1985, Basic Books.

Thompson R. A., Early attachment and later development: Familiar questions, new answers, in: J. Cassidy, P. R. Shaver (eds.), Handbook of attachment, New York 2008, Guilford, pp. 348-365.

Verny T. R., Tomorrow's baby, New York 2002, Simon \& Schuster.

Winnicott D. W., Playing and reality, London 1971, Routledge.

Winnicott D. W., On the child, Cambridge 2002, Perseus Books Group. 
